\title{
Documentação fotográfica intra-operatória
}

\section{Intraoperative photographic documentation}

\author{
Marcelo Versiani Tavares ${ }^{1}$ \\ Fernando Barbosa CotTa ${ }^{2}$ \\ André Giannini CorrêA ${ }^{2}$ \\ Rafael Carlos Barra \\ GOMES $^{2}$ \\ Virgínia Magalhães de \\ BARROS $^{2}$ \\ Mariana Rabelo Maia ${ }^{3}$ \\ Luiz Eduardo Toledo \\ AvelaR $^{4}$ \\ Gustavo Graça \\ Mercadante 5
}

Trabalho realizado no Hospital Lifecenter, Belo Horizonte, MG,

Brasil.

Artigo submetido pelo SGP (Sistema de Gestão de Publicações) da RBCP.

Artigo recebido: 4/4/2010

Artigo aceito: $30 / 8 / 2010$

\begin{abstract}
RESUMO
O prontuário médico é um dever ético, sendo a documentação fotográfica uma extensão deste, e muitas vezes de grande importância, principalmente na Cirurgia Plástica. A documentação fotográfica pré-operatória e pós-operatória em Cirurgia Plástica é rotineiramente utilizada, enquanto a fotografia intra-operatória ainda não, apesar de facilitar e auxiliar as divulgações científicas e ser uma forte aliada nos registros médicos. O presente artigo apresenta uma forma simples, de baixo custo, capaz de permitir a documentação fotográfica intra-operatória com ótima qualidade, preservando-se o ângulo de visão do próprio cirurgião, com menores riscos de contaminação, demandando menor tempo de interrupção e independente de auxiliares externos. Tal ferramenta consiste na associação de uma capa à prova de água à câmera fotográfica digital.
\end{abstract}

Descritores: Fotografia. Documentação. Registros médicos.

\section{ABSTRACT}

The medical records are an ethic obligation and the photographic documentation is part of it; many times with huge importance, mainly in Plastic Surgery. The preoperative and postoperative photographic documentation are commonly used in Plastic Surgery, while the intraoperative photograph is not yet, although it helps and facilitates scientific reports and it is a strong ally in medical records. The present article shows a simple way of taking intraoperative photography documentation, with high quality, low cost, preserving the surgeons angle of vision, with low risk of contamination, demanding less time of interruption and independent of external. This tool consists simply the association of a waterproof case with the digital camera.

Keywords: Photography. Documentation. Medical records.

\section{INTRODUÇÃO}

O prontuário médico representa para o paciente o fiel registro de seus diagnósticos, tratamentos e evoluções; enquanto que, para o médico, além de um dever, representa uma fonte de informações científicas e um grande aliado nas potenciais lides jurídicas ${ }^{1}$. O registro do ato cirúrgico, por meio de sua descrição, é fundamental sob todos os aspectos, mas, infelizmente, é muitas vezes negligenciado pelos profissionais médicos ${ }^{2}$.

Oobjetivodopresente estudoédemonstraruma ferramenta simples, de baixo custo, capaz de permitir a documentação fotográfica intra-operatória pelo próprio cirurgião com uma câmera digital.

\section{MÉTODO}

Utilizamos uma câmera digital (DSC-W80 - Cybershot Sony de 7.2 megapixels) e uma capa à prova de água (DICAPAC - WP400 Goldship, com lentes de policarbonato), a qual foi esterilizada separadamente em óxido de etileno.

Posteriormente, durante a montagem do instrumental cirúrgico, introduzimos a câmera dentro da capa à prova

1. Membro Titular da Sociedade Brasileira de Cirurgia Plástica (SBCP); Coordenador do Serviço de Cirurgia Plástica do Hospital Lifecenter, Assistente do Serviço de Cirurgia Plástica do Hospital Felício Rocho, Belo Horizonte, MG, Brasil.

2. Membro Especialista da SBCP; Médico Assistente do Serviço de Cirurgia Plástica do Hospital Lifecenter, Belo Horizonte, MG, Brasil.

3. Acadêmica de Medicina; Estagiária do Serviço de Cirurgia Plástica do Hospital Lifecenter, Belo Horizonte, MG, Brasil.

4. Membro Titular da SBCP, Coordenador do Serviço de Cirurgia Plástica do Hospital Socor, Belo Horizonte, MG, Brasil.

5. Advogado; Especialista em Responsabilidade Civil na Área da Saúde, Belo Horizonte, MG, Brasil. 


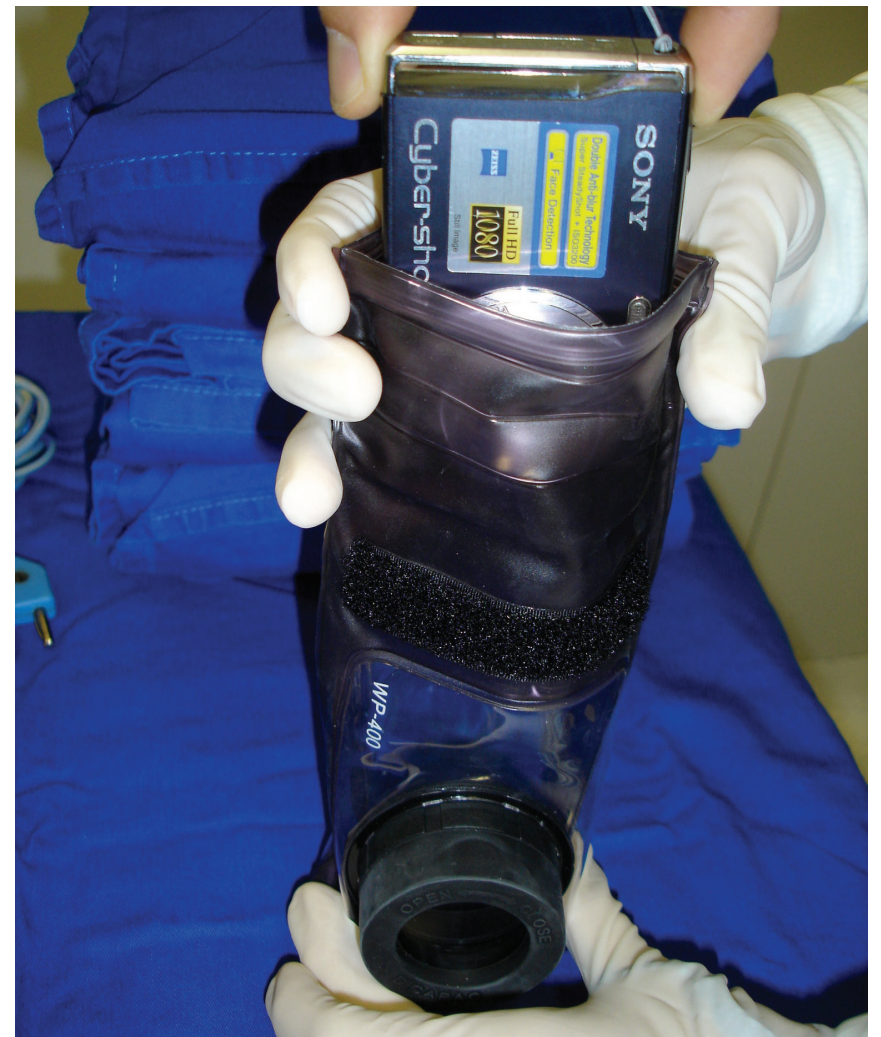

Figura 1 - Introdução da máquina de fotografia na capa à prova de água durante a montagem da mesa de instrumental cirúrgico.

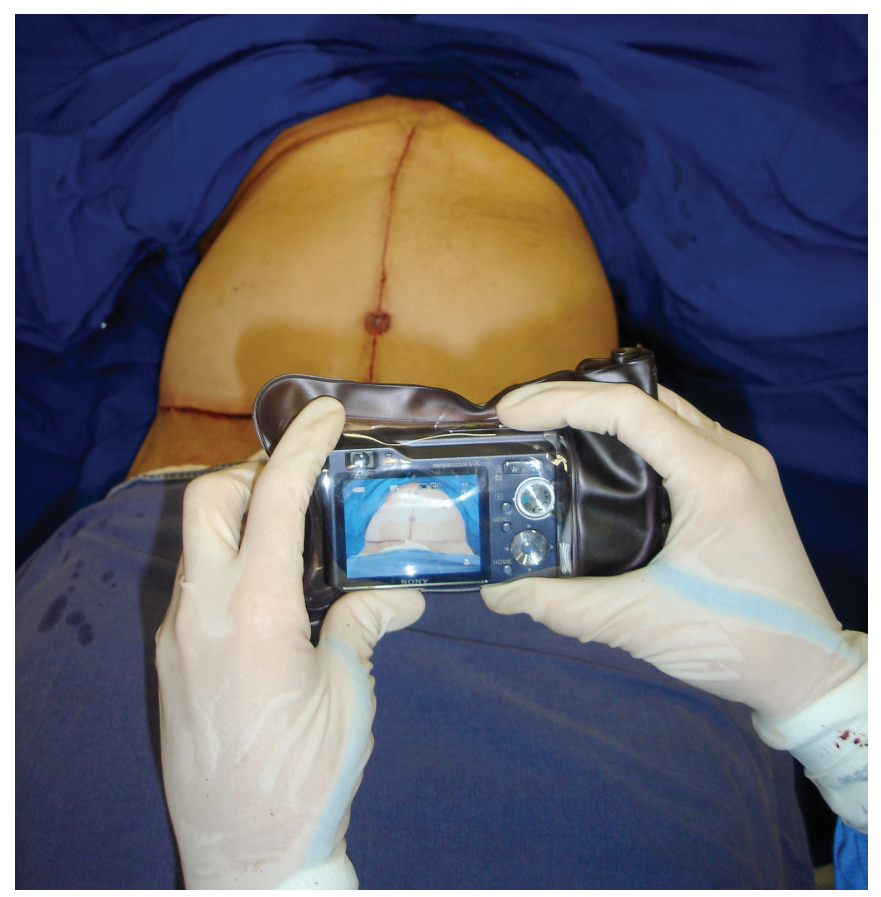

Figura 2 - Demonstração da facilidade de manipulação do equipamento no campo cirúrgico, com acessibilidade a todos os recursos e preservação de visão ampla da tela de cristal líquido. de água e fechamos o velcro, isolando a mesma. Esta capa preserva todos os recursos integralmente acessíveis, possibilita ampla visão da tela de cristal líquido, sem riscos de dano à câmera e, principalmente, sem risco de contaminação do campo cirúrgico (Figuras 1 e 2).

\section{DISCUSSÃO}

O prontuário é um dever ético do médico ${ }^{1}$, sendo a fotografia uma ferramenta cada vez mais importante, principalmente na Cirurgia Plástica, para o fiel registro das diversas etapas do tratamento, desde o pré-operatório até o pós-operatório e agora também no intra-operatório ${ }^{2-4}$.

A utilização de uma capa à prova de água em uma câmera fotográfica digital permite ao próprio cirurgião registrar as diversas etapas cirúrgicas sob o seu próprio ângulo de visão ${ }^{3,4}$; assegura a qualidade das imagens, uma vez que as mesmas podem ser visibilizadas imediatamente e repetidas se necessário $^{2,3}$; dispensa a necessidade de colaboradores externos, nem sempre dispostos ou disponíveis a fazê- $10^{3}$; minimiza o tempo gasto para tal e, consequentemente, do tempo de paralização do ato cirúrgico ${ }^{4,5}$; reduz o custo ${ }^{5}$ minimiza os riscos de infecção e assegura o fiel registro fotográfico dos procedimentos $^{3}$.

No âmbito científico, a documentação fotográfica intraoperatória representa um manancial exuberante de informações, auxiliando a ilustração de trabalhos científicos, facilitando a comunicação entre profissionais e facilitando a divulgação bem como o entendimento de novas técnicas ${ }^{3,4}$.

Não obstante a todas as vantagens técnicas e ao dever ético, a documentação fotográfica intra-operatória também é uma forte aliada dos profissionais médicos em eventuais demandas judiciais.

\section{CONCLUSÃO}

O prontuário é um dever ético do médico, sendo a descrição cirúrgica, apesar de parte integrante do mesmo, muitas vezes negligenciada.

A capa à prova de água é uma ferramenta simples e de baixo custo, capaz de viabilizar a documentação fotográfica intra-operatória com qualidade e baixo risco de contaminação; auxiliando e facilitando, assim, as divulgações científicas, além de contribuir sobremaneira com o cumprimento do dever ético, resguardando ainda mais os profissionais em eventuais demandas jurídicas.

\section{REFERÊNCIAS}

1. Conselho Federal de Medicina. Resolução 1246, de 08 de janeiro de 1988 - Dispõe sobre o Código de Ética Médica. Diário Oficial da União; Poder Executivo, Brasília, 26 de janeiro de 1988; seção 1: 1574-7. 
2. Rhodes ND, Southern SJ. Digital operation notes: a useful addition to the written record. Ann Plast Surg. 2002;48(6):571-3.

3. Raigosa M, Benito-Ruiz J, Fontdevila J, Ballesteros JR. Waterproof camera case for intraoperative photographs. Aesthetic Plast Surg. 2008;32(2):368-70.
4. Cakir B, Akan M, Taylan G, Aköz T. Easy perioperative photography by digital camera covered with a sterile nylon bag. Plast Reconstr Surg. 2005;115(6):1802-4

5. La Scala GC, Fisher DM. An inexpensive sterile cover for digital photography in the operating room. Plast Reconstr Surg. 2001;108(7):2182-3.

\section{Correspondência para:}

Marcelo Versiani Tavares

Av. Contorno, 4747, sl 1711-1712 - Serra - Belo Horizonte, MG, Brasil - CEP 30110-090

E-mail:m.versiani@yahoo.com.br 